\title{
Exploring the hydrothermal evolution of seawater-exposed ultramafic rocks and the abundance of microbial activity
}

ESTHER M. SCHWARZENBACH ${ }^{1}$, GRETCHEN L. FRÜH GREEN $^{2}$, CHIARA BOSCHI ${ }^{3}$ AND MONICA VOGEL ${ }^{2}$

${ }^{1}$ Freie Universität Berlin

${ }^{2}$ ETH Zurich

${ }^{3}$ Consiglio Nazionale delle Ricerche (IGG-CNR)

Presenting Author: esther.schwarzenbach@fu-berlin.de

Interaction of fluids with ultramafic rocks has a major impact on the global geochemical cycles and supports life due to the release of chemical species that serve as an energy source for chemolithoautotrophic communities. Along ocean ridge spreading centers, seawater-exposed peridotites undergo an extensive mineralogical and chemical transformation associated with the formation of serpentinites and ophicalcites. Such transformations can be investigated in ocean floor samples and are well-exposed in ophiolite sequences. Here, I will compare recent results from the Atlantis Massif (IODP Exp. 357), several ODP (Ocean Drilling Program) drill cores and the Northern Apennine ophiolite in Italy. Geochemical investigations show that at many of these locations fluids of different origin induce a complex history of serpentinization, carbonation and Simetasomatism to variable degrees. In addition, in oceancontinent transition zones and during initial stages of the opening of ocean basins basement-derived fluids can interact with peridotites as imprinted in elevated ${ }^{87} \mathrm{Sr} /{ }^{86} \mathrm{Sr}$ signatures. Bulk rock and in situ isotope measurements of sulfur, carbon and oxygen combined with detailed mineralogical and petrological investigations further provide constraints on how the occurrence of microbial activity (reflected in distinct sulfur isotope signatures) is linked to factors such as temperature, redox conditions, water-rock ratios or magmatic activity. Thus, the correlation between mineralogical, petrological and geochemical investigations allows us to constrain the hydrothermal evolution of peridotites to serpentinites and eventually ophicalcites during their continuous uplift and exposure on the ocean floor. Furthermore, it allows us to constrain the stages of water-rock interaction that are favorable to support a deep biosphere within peridotite-hosted hydrothermal systems. 